\title{
Performance Improvement Methods: Not Just For Maintenance of Certification
}

\author{
Anthony Chiodo, MD, MBA, Eric Rosenhauer, MBA, MHA, \\ Gregory Worsowicz, MD, MBA
}

The 2008-11 Enhanced Public Trust Initiative of the American Board of Medical Specialties is a call for greater oversight and accountability of board-certified medical physicians to assure quality patient care and management [1]. The American Board of Medical Specialties Maintenance of Certification (MOC) program is designed to promote excellence in patient care and to support physicians' commitment to lifelong learning and continued professional development. The MOC process also assures the public that board-certified physicians remain current in knowledge of their specialty and that it has been put into practice to fulfill the directive by the Enhanced Public Trust Initiative. Although the issues of quality of care, lifelong learning, and professional development are essential for physicians, there is debate over how one measures these issues.

The current state of $\mathrm{MOC}$ requires physicians to participate in a 4-part process:

I. Licensure and professional standing

II. Lifelong learning and self-assessment

III. Cognitive expertise

IV. Practice performance assessment

In short, a physician must keep a valid license, complete education and selfassessments, take a "high-stakes" test, and demonstrate performance improvement. For part IV, physicians "are evaluated in their clinical practice according to specialtyspecific standards for patient care. They are asked to demonstrate that they can assess the quality of care they provide compared to peers and national benchmarks and then apply the best evidence or consensus recommendations to improve that care using follow-up assessments [2]."

The American Board of Physical Medicine and Rehabilitation (ABPM\&R) currently requires Practice Improvement Projects (PIP) as a way to fulfill part IV, Practice performance assessment. Initially, a PIP may appear burdensome, but the process and the tools it requires can be applied to other areas of one's practice; hence, there often is a hidden value beyond the requirement for MOC. Performance improvement, in general, is a methodology that requires utilization of improvement tools and understanding of processes. It takes time to learn, time to implement, and time spent on evaluating errors and processes that result in yet more time being required to make appropriate changes. The silver lining is that the PIP can be the path to continuous improvement for a practice.

PIPs require defining a project, selecting a team, setting goals for improvement, initiating a pilot, and evaluating the result. To meet the minimum requirements of certification, a physician could complete a project and "call it a day"; however, with some planned effort, gains in practice performance can be realized. New skill sets can be developed and used, and practice processes can be refined and become more efficient. Practices may become less expensive to run, and process or patient outcomes improved. That is the point at which return on the investment of time spent is realized!

By improving the efficiency of the billing service, correcting errors in patient scheduling, streamlining the process of prior approvals, maximizing the frequency of laboratory monitoring, or ensuring the adherence to clinical guidelines, the results of a PIP can lead to continuous improvement in all or any aspects of clinical practice. These same methodologies can lead to improved patient care and a stronger bottom line. For example, an audit can identify that hemoglobin AlC levels are not checked regularly in patients with diabetes, that $20 \%$ of bills are returned unpaid for incorrect coding, or that
A.C. Department of PM\&R, University of Michigan Hospital, Ann Arbor, Ml Address correspondence to: A.C.; e-mail: tchiodo@ med.umich.edu

Disclosure: nothing to disclose

E.R. Department of Performance Improvement, University of Missouri, Columbia, MO Disclosure: nothing to disclose

G.W. Department of PM\&R, University of Missouri, Columbia, MO

Disclosure: 9, chair of AAPM\&R Quality Practice and Policy Committee

Disclosure Key can be found on the Table of Contents and at www.pmrjournal.org 
Table 1. Common performance improvement methodologies

\begin{tabular}{|c|c|c|c|}
\hline & PDCA & Lean & Six Sigma \\
\hline Definition & $\begin{array}{l}\text { Cyclical product and/or process } \\
\text { improvement emphasis on } \\
\text { control }\end{array}$ & $\begin{array}{l}\text { Elimination of waste, speed, } \\
\text { efficiency }\end{array}$ & $\begin{array}{r}\text { Reduction in defects and } \\
\text { variation, data driven }\end{array}$ \\
\hline Methodology & $\begin{array}{l}\text { Deming-Shewhart PDCA cycle } \\
\text { - Plan } \\
\text { - Do } \\
\text { - Check } \\
\text { - Act }\end{array}$ & $\begin{array}{l}\text { Value stream mapping; 5S: } \\
\text { - Sort } \\
\text { - Straighten } \\
\text { - Scrub } \\
\text { - Systematize } \\
\text { - Sustain }\end{array}$ & $\begin{array}{l}\text { DMAIC } \\
\text { - Define } \\
\text { - Measure } \\
\text { - Analyze } \\
\text { - Improve } \\
\text { - Control }\end{array}$ \\
\hline
\end{tabular}

PDCA = plan, do, check, act; DMAIC = define, measure, analyze, improve, control.

$10 \%$ of procedure appointments are cancelled due to lack of prior approval. Proactive process improvement can lead to huge benefits in patient outcome and practice management but to do so requires a philosophy of continuous improvement, processes that work well, dedicated people, and a commitment to problem solving to root out problems that interfere with excellence.

\section{COMMON PERFORMANCE IMPROVEMENT METHODOLOGIES}

Plan Do Check Act (PDCA), Lean, and Six Sigma are 3 of the most common performance improvement methodologies used in health care today. Physicians in small practices or in large organizations should have some familiarity with these methods. Each has its place, and each approach, when deployed properly, can create and sustain improvement (see Table 1).

The PDCA concept was originally developed by Walter Shewhart, a pioneering statistician and is often referred to as the Shewhart cycle. It was popularized and promoted very effectively by W. Edwards Deming [3]. The process is based on a scientific approach with a systematic method of problem recognition, data collection, and testing of hypotheses. The components are defined as the following:

Plan. The establishment of the objectives and processes necessary to deliver the desired results.

Do. Implement the new process often on a small scale or pilot program.

Check. The measurement of the progress and results, noting any difference in performance.

Act. Analyze the differences to determine their cause. Continue the cycle again, adjusting the scope as needed to improve.

Although PDCA is very common in health care today, its roots, like most improvement methods, began in manufac- turing. Japanese manufacturing learned the PDCA method from Deming and quickly adopted and improved it. What followed was the Toyota Production System or what is often referred to as Lean [4].

Lean is the relentless pursuit of the perfect process through waste elimination. Its key principles are specifying value from the customer's perspective, identifying the value stream for each process and/or product, making value flow without interruptions, letting customers "pull" value, and pursuing perfection. Value is often cited and something for which the customer is willing to pay. Therefore, if the customer is not willing to pay for it, it is nonvalue adding or waste. There are 8 types of wastes or "muda" as described in Japanese. These are (with examples referencing health care):

- Defects: medication errors, resticks.

- Overproduction: use of tests or equipment that is not required to make a decision.

- Inventories: laboratory specimens batched, dictation waiting for transcription, excessive supplies.

- Movement: looking for medications, missing equipment.

- Excessive Processing: retesting, multiple bed moves, repeating administrative tasks.

- Transportation: moving patients to laboratories or test versus POC testing.

- Waiting: appointments, access, ED test results.

- Underutilization: physicians transporting patients.

Aside from value stream mapping, one of the main tenets within Lean is $5 \mathrm{~S}$, a discipline for creating a clean, safe, orderly high-performance work environment. The English version of $5 \mathrm{~S}$ is the following: sorting, set in order, shining, standardizing, and sustaining. The $5 \mathrm{~S}$ methodology enables waste to be readily visible, which creates opportunities for improvement. 
A critical component of Lean is that, with implementation of a new process, there must be real-time data collection and an opportunity to correct the process based on those results, so that each step can be done efficiently and correctly from the start. In medicine, it could be a computer red flag that alerts the physician that a patient has not had his INR checked in the allotted time, rather than waiting until the next visit (allowing the time to pass) when a potentially devastating medication complication could occur. This takes technology and creativity, and can greatly improve physicians' efficiency by having systems set up to help manage some of the many daily details more efficiently. These systems are highly visible and have people empowered to act on the information as it occurs to make sure the work is completed correctly.

To accomplish this, a team must be conferred that understands the process first hand, can identify its customers, and knows how those customers are served by the process; thus, the team should not be composed of only administrators. In a recent project that evaluated the admissions process to one of the author's (A.C.) inpatient rehabilitation unit, initial thought was to develop a team largely of physicians. Once the process was evaluated in real time, it became clear that unit clerks, nurses, billing office staff, admissions coordinators, and housekeeping staff were essential team members and needed more representation on the team. This principle is true of any performance improvement project; assignment of the team members is critical to the success of the group and requires thoughtful consideration. A flow diagram, or value stream map, of the process was then developed. The team identified steps in the process that were of value to the customer and which steps were wasteful or took too much time, energy, uncertainty, movement, or waiting. Waste can also be defined by too many errors (or defects), unused employee creativity, or too much inventory held [5]. Eliminating these steps leaves just the value-added steps and a much more nimble and efficient process.

A best practice of value stream mapping is root cause analysis. First, identify waste but then honestly and objectively determine if the cause can be eliminated. Continually questioning "Why?" until the real reason that the step is not working is uncovered is the only way to uproot the biases and myths that block real change. In this process, one starts with the many possible causes, narrowing these down to likely causes and, with continued inquiry, ultimately discovers the root cause [5]. In an analysis of one of the author's (A.C.) inpatient rehabilitation discharge process, a concern was identified that the patient's families came in too late on the day of discharge to achieve a discharge in the morning. Asking "Why?" over 3-4 different steps finally identified the root cause: the team never made this a family expectation at the time of admission. Simply speaking, families were never actually told to be there early on discharge day, so how could
Table 2. Six Sigma

\begin{tabular}{cc}
\hline Sigma Level & Defects Per Million Opportunities \\
\hline 1 & 690,000 \\
2 & 308,538 \\
3 & 66,807 \\
4 & 6210 \\
5 & 233 \\
6 & 3.4 \\
\hline
\end{tabular}

they have been expected to comply (hence, setting expectation).

The Six Sigma tool has its beginnings in manufacturing as well. Although it was popularized by Jack Welch of General Electric, it was started by Bill Smith at Motorola in 1986 [6] It is based on PDCA and Deming's concept of reducing process variation. Six Sigma is a statistical measure of quality that expresses how close a process or product comes to its quality goal. It is a process-based approach for continuous improvement that can often enable a cultural change. Quantitatively, it means that a product or process generates 3.4 defects per million opportunities. A process performing at 6 sigma levels means there are 6 standard deviations from the process mean or specification limit (see Table 2).

Most U.S. businesses function at a 3 sigma range. A 6 sigma function would be a 20,000 times improvement from 3 sigma. Six Sigma methodology is made up of 5 phases: define, measure, analyze, improve, and control (known as DMAIC).

During the define phase, teams establish customer expectations by gathering the voice of the customer, and translate these into critical to quality characteristics, and create a high-level process map called a SIPOC (suppliers, inputs, process, outputs, customers). A SIPOC for one of the author's (E.R.) recent project to improve performance of a preoperative program is provided in Figure 1.

The next phase is measure, which questions how the process is performing. Baselines are established, and measurement systems are tested.

In the analyze phase, hypotheses are developed and tested on the sources of variation and cause-effect relationships [7] The goal is to statistically identify links between the targeted input and process $(\mathrm{X})$ variables and the dependant output $(\mathrm{Y})$ measures. The goal is to sort out the critical process (X) variables.

After data analysis, the improve phase begins in which potential solutions are identified and their impact on the output is tested. After piloting possible solutions and verifying through data that a positive statistically significant change has occurred, the statistical solution is then translated back into a practical business solution.

The final phase is control. This is often overlooked in most other improvement methods. In this phase, the objective is to identify how to sustain the improvement. Ongoing monitor- 


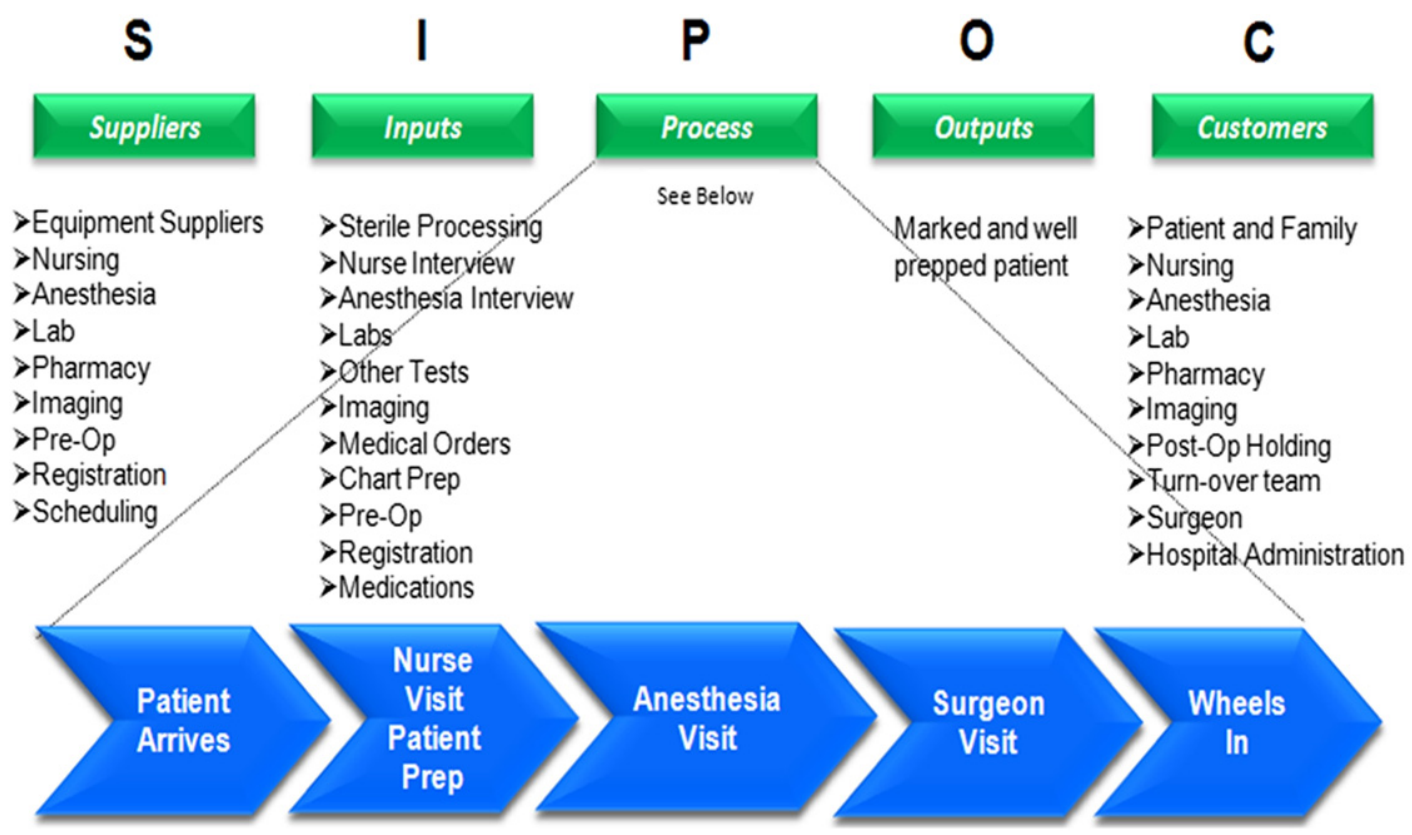

Figure 1. High level process map SIPOC diagram.

ing may be required and results in the application of control charts.

The 3 discussed methodologies, PDCA, Lean, and Six Sigma, are rooted in a discipline and continuous process improvement. These methods can be applied to patient care, practice operation, management, or to a large health system. As health care continues to adopt these improvement methodologies, it is important for physicians to have a working knowledge of these methods, applications, and their unique terminology (see Suggested Readings).

With the national spotlight focused on improving and reporting the quality and safety of patient care, fostering lifelong learning is critical for physicians. Within the MOC process, additional value toward improving practice efficiency and patient outcomes can also be realized. As clinicians complete the PIP component of the MOC requirements, the key is to decide which performance improvement method works for their situation and to stay with it through constant monitoring and analysis. To assist with a PIP, the Web sites of ABPM\&R and American Academy of Physical Medicine and Rehabilitation (AAPM\&R) provide sample presentations of requirements $[8,9]$. The ABPM\&R plans to offer Clinical Care PIP workshops at future meetings of the AAPM\&R and Association of Academic Physiatrists [8] The AAPM\&R also provides access to an outline and assistance for doing a PIP in the area of low back pain; PIPs for stroke, deep venous thrombosis, and osteoarthritis management are in development [9]. Like any new clinical skill, there needs to be education and practice to become proficient with an application. As health care continues to adopt many of the performanceimprovement tools that have been used for years by other industries, educational forums and mechanisms for assistance will continue to evolve.

\section{REFERENCES}

1. American Board of Medical Specialties. Available at http://abms.org/. Accessed January 20, 2011.

2. $M O C$ Competencies and Criteria. Available at http://abms.org/Maintenance_of_Certification/MOC_competencies.aspx. Accessed January 20 , 2011

3. Johnson CN, ed. The benefits of PDCA. Quality Progress May 2002. Available at http://asq.org/quality-progress/2002/05/problem-solving/ the-benefits-of-pdca.html. Accessed January 20, 2011.

4. Womack JP, Jones DT, Roos D, Massachusetts Institute of Technology. The machine that changed the world: based on the Massachusetts Institute of Technology 5-Million Dollar 5-Year Study on the Future of the Automobile. New York: Rawson Associates; 1990.

5. Liker JK, Meier D. The Toyota Way Fieldbook: A Practical Guide for Implementing Toyota's 4Ps. New York: McGraw-Hill; 2006.

6. The Inventors of Six Sigma. Archived from the original on November 6, 2005. Available at http://web.archive.org/web/20051106025733/http:/www. motorola.com/content/0,3079,00.html. Accessed January 20, 2011.

7. Duhig J. Why We Need Six Sigma in Healthcare. 2003. Available at www. vahimss.org/presentations/duhig.ppt. Accessed December 1, 2010.

8. American Board of Physical Medicine and Rehabilitation (ABPM\&R). Available at https://www.abpmr.org/diplomates/pp_samples.html. Accessed December 27, 2010.

9. American Academy of Physical Medicine and Rehabilitation (AAPM\&R) Academe. Available at http://me.e-aampr.org/MOC.aspx. Accessed December 27, 2010. 


\section{SUGGESTED READINGS}

Womack JP, Jones DT. Lean Thinking: Banish Waste and Create Wealth in Your Corporation. 1st Free Press ed. New York: Free Press; 2003.

Womack JP, Jones DT, Roos D, Massachusetts Institute of Technology. The Machine That Changed the World: Based on the Massachusetts Institute of Technology 5-Million Dollar 5-Year Study on the Future of The Automobile. New York: Rawson Associates; 1990.

Belasco JA. Teaching the Elephant to Dance: Empowering Change in Your Organization. 1st ed. New York: Crown; 1990.
Katzenbach JR, Beckett F. Real Change Leaders: How You Can Create Growth and High Performance at Your Company. 1st pbk. ed. New York: Times Business; 1996.

Katzenbach JR, Smith DK. The Wisdom of Teams: Creating the HighPerformance Organization. New York: HarperBusiness Essentials; 2003.

Block P. Stewardship: Choosing Service Over Self-Interest. 1st ed. San Francisco: Berrett-Koehler Publishers; 1993.

Collins JC. Good to Great: Why Some Companies Make the Leap-And Others Don't. 1st ed. New York: HarperBusiness; 2001. 